\title{
ARTIGO
}

\section{Mobilidade e Estrutura de Classes no Brasil Contemporâneo}

\section{Resumo}

Este artigo apresenta análises sobre estrutura de classes e mobilidade social no Brasil usando os dados mais recentes disponíveis. A evolução da estrutura de classes entre as décadas de 1970 e 2000 é apresentada, indicando que medida em termos das ocupações houve uma diminuição gradual das classes de trabalhadores manuais qualificados e profissionais. Esta mudança, no entanto, não significa que a sociedade brasileira passou a ser predominantemente de classe média como vem sendo defendido por alguns cientistas sociais. Além disso, o artigo argumenta que informações sobre mobilidade intergeracional são fundamentais para definir as principais clivagens de classe. Nesse sentido, o artigo descreve o padrão de fluidez social no Brasil que determina as desigualdades de oportunidades de mobilidade social e os principais pontos de fechamento social na estrutura social brasileira. O padrão vertical ou hierárquico é o que melhor descreve a fluidez social no país, o que implica em dizer que a distância entre as classes em termos de mobilidade intergeracional é fundamental. O papel mediador entre classes de origem e de destino desempenhado pela educação alcançada também é apresentado. A maioria das análises é baseada em dados provenientes da Pesquisa Dimensões Sociais das Desigualdades (PDSD2008), mas dados das Pesquisas Nacionais por Amostragem Domiciliar (PNADs) de 1973, 1982, 1988, e 1996 também são apresentados.

Palavras-chave: Mobilidade social. Classes. Desigualdades sociais. Fluidez social. Brasil.

* Universidade Estadual do Rio de Janeiro, Rio de Janeiro, Brasil. 


\title{
Social Mobility and Class Structure in Contemporary Brazil
}

\begin{abstract}
This paper examines class structure and social mobility in Brazil using the most current data available. It is presented the evolution of class structure from the 1970s to 2000, which indicates that if measured in terms of the occupations, there was a gradual decrease in the classes of professionals and skilled manual workers. This change, however, does not mean that Brazilian society has become predominantly comprised by a middle class, as some social scientists have argued. We claim here that information about intergenerational mobility is essential to define the main cleavages of class. Thus, the article describes the pattern of social fluidity in Brazil, which determines both the inequality in opportunities for social mobility and the main points of social closure in Brazilian social structure. The social fluidity in the country is best described by the vertical - or hierarchical - pattern, which implies that the distance between social classes in terms of intergenerational mobility is fundamental. The role played by achieved education in mediating between the origin and destination classes is also presented. The analyzes are mostly based on data from the survey Social Dimensions of Inequality (PDSD-2008), although data from the national survey by household sampling (PNAD) for the years1973, 1982, 1988, and 1996 are also presented.
\end{abstract}

Keywords: Social mobility. Classes. Social inequality. Social fluidity. Brazil.

\section{Introdução}

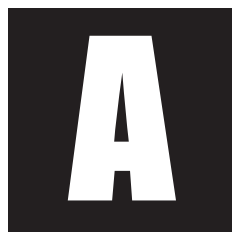

s análises sobre mobilidade de classe desempenham dois papéis nos estudos de estratificação social. Por um lado, servem para determinar o grau de abertura ou fechamento da estrutura de classes, na medida em que descrevem a força da associação entre classes de origem (dos pais) e de destino (dos filhos). Esta associação também é uma medida da desigualdade de oportunidades ou da fluidez social. Em estudos comparativos ao longo do tempo ou entre países, é possível verificar 
diferenças no grau de fluidez social. Um estudo recente sobre o Brasil revela que houve diminuição da desigualdade de oportunidades entre as décadas de 1970 e 2000 (Ribeiro, 2012). Por outro lado, permitem determinar as principais barreiras à mobilidade intergeracional, que, por sua vez, também podem ser vistas como divisões básicas da estrutura de classes de uma sociedade.

As principais clivagens na estrutura de classes não são dadas apenas pelos recursos (econômicos, educacionais e sociais) disponíveis, mas também pela forma como estes recursos contribuem para a reprodução intergeracional das classes sociais. Desvendar quais barreiras dificultam a mobilidade intergeracional é fundamental para descrever melhor as principais divisões de classe que caracterizam a estrutura social. Em algumas sociedades, há barreiras entre o topo e o meio, e entre o meio e a base da estrutura de classes; em outras, entre o meio e o topo, mas não entre o meio e a base; e etc. Às vezes, as principais barreiras estão entre setores como, por exemplo, entre rurais e urbanos, ou entre manuais e não-manuais, e assim por diante. Sua definição é importante para desvendar os principais pontos de fechamento social e clivagens de classe. Tais barreiras tendem a ser mais ou menos rígidas (ou, inversamente, fluidas), mas, em geral, não se modificam muito em sociedades industriais modernas. $\mathrm{O}$ objetivo deste artigo é avançar análises para descrever as barreiras que caracterizam a estrutura de classes brasileira na década de 2000, a partir não apenas dos recursos disponíveis em cada classe, mas também da análise do padrão de mobilidade de classe brasileiro.

Dois estudos anteriores analisaram as principais barreiras à mobilidade de classe impostas por um padrão geral não-hierárquico de estruturação das classes sociais (Ribeiro, 2007; Scalon, 1999). Esses estudos mostraram que um modelo fazendo divisões entre diversos setores - o assim chamado core model of social fluidity (Erickson, 1993) - descrevia bem o padrão 
de fluidez social e caracterizava as principais divisões de classe no Brasil em 1988 (Scalon, 1999) e entre 1973 e 1996 (Ribeiro, 2007). Um desses estudos (Ribeiro, 2007), no entanto, mostra que a dimensão hierárquica entre as classes e a tendência à imobilidade em algumas classes descreve ainda melhor o padrão brasileiro. De fato, há uma antiga controvérsia na literatura opondo duas perspectivas no estudo sobre mobilidade e classes sociais. A primeira afirma que a fluidez social se estrutura de acordo com algumas barreiras, dificultando a mobilidade entre certas classes específicas e facilitando os movimentos entre algumas outras classes (Erickson, 1993; 1992a; 1992b). Essa abordagem sugere que há um padrão topológico, que inclui tanto divisões verticais quanto horizontais para definir as principais clivagens de classe e canais de fluidez social. Uma perspectiva alternativa sugere que a dimensão ou ordenação hierárquica (vertical) entre as classes sociais é o principal fator determinando a fluidez social (Hout, 1984; 1989; Hout; Hauser, 1992). Consequentemente, as principais clivagens seriam determinadas pela distância entre as classes. Neste artigo apresento análises para o Brasil na década de 2000, com o objetivo de verificar qual perspectiva mais se adéqua ao caso brasileiro.

Uso um esquema com sete grupos de classe para analisar a estrutura social brasileira. Atualmente há, no Brasil, um enorme debate sobre a expansão das classes médias, em geral observadas em termos de renda média. A definição sociológica de classes sociais enfatiza distinções na posição que os trabalhadores ocupam na estrutura produtiva em termos de propriedade, qualificações e trabalho manual, por um lado, e das principais barreiras à mobilidade intergeracional como fontes de estruturação de classes, por outro lado. Assim, a ideia de classes médias nos estudos sociológicos sobre estraficação social depende de uma série de análises e definições envolvendo a estrutura ocupacional e os padrões de mobilidade intergeracional. Os dados que analiso permitem definir claramente estas ocupações e verificar 
quais são as principais barreiras à mobilidade. Dessa forma, as análises aqui desenvolvidas permitem verificar em que medida houve uma expansão das classes médias entre os anos 1970 e 2000, considerando diversos aspectos das classes sociais, inclusive os padrões de mobilidade. Para complementar essas análises, também descrevo o efeito mediador, entre origem e destino de classe, da educação alcançada pelos indivíduos.

O artigo está dividido em cinco partes, sendo a primeira esta introdução. A segunda apresenta as análises sobre a estrutura de classes, e a terceira apresenta os modelos usados para analisar o padrão de fluidez no Brasil para homens e mulheres. Alguns modelos são inspirados pela perspectiva topológica dos estudos de mobilidade, enquanto outros pela hierárquica ou vertical. A avaliação do ajuste destes modelos permite verificar qual das duas perspectivas melhor descreve o padrão de fluidez e a estrtura de classes brasileira. A quarta parte discute o efeito mediador da educação na mobilidade social, e a última seção traça as principais conclusões.

\section{Estrutura de Classes no Brasil}

Em 1994, se iniciou uma tendência de diminuição da desigualdade de renda no Brasil, que se acentuou ainda mais a partir de 2002. Houve um aumento generalizado da renda, que fez com que mais de $50 \%$ da população passasse a estar no meio da distribuição. Com estas modificações, o governo começou a divulgar o aumento da classe média no Brasil. O principal trabalho propagandeando essa enorme expansão foi o livro de Neri (2011) que utiliza amplamente o termo nova classe média. Apesar do tom ufanista, o livro apresenta análises muito interessantes e sérias sobre a distribuição de renda no Brasil e realmente indica que houve um aumento significativo do número de pessoas e famílias com renda no meio da distribuição. A pobreza, medida em termos de renda, também diminuiu significativamente. 
Alguns sociólogos e economistas contestaram essa ideia, na medida em que não concordam com a visão de que a classe média seja medida apenas em termos de renda. Uma longa tradição das ciências sociais sugere que classes sociais devem ser definidas em termos das relações de trabalho em que as pessoas se encontram, bem como de certa identidade cultural e chances de vida também ligadas a essas relações de trabalho. Nesse sentido, alguns trabalhos criticaram fortemente a ideia de que houve uma enorme melhora, e que o Brasil passou a ser uma sociedade de classe média. Um economista, Pochman (2012), escreveu um pequeno livro dizendo que as condições de trabalho não melhoraram tanto quanto afirma Neri (2011). O livro levanta pontos fundamentais e realmente indica que ainda há muitos trabalhadores em ocupações e situações de emprego pouco qualificadas e que estão no setor de serviços. Em outras palavras, o aumento da demanda por trabalhadores pouco qualificados foi um fator importante elevando a renda, mas não houve uma mudança significativa da qualidade dos empregos. Outro trabalho relevante é o do sociólogo Souza (2012). Apesar de insistir em desqualificar as análises quantitativas, o que considero um equívoco, a pesquisa de Souza (ibidem) tem o mérito de mostrar a persistência de uma cultura de classe que está longe de ser uma representação social do que poderia ser chamado de classe média. O trabalho qualitativo desenvolvido por Souza é muito interessante, justamente porque revela aspectos subjetivos da situação de classe em que se encontram brasileiros ocupando posições intermediárias e baixas na estratificação social. Uma terceira pesquisa, que usa o mesmo esquema de classes que adoto neste artigo, é a dos sociólogos Scalon e Salata (2011). Esses autores usam as Pesquisas Nacionais por Amostragem Domiciliar (2002; 2009) para mostrar mudanças na estrutura de classes, medidas de acordo com o esquema CASMIN ${ }^{1}$, com seis classes sociais.

${ }^{1}$ Inicialmente foi denominado de esquema EGP porque foi formulado por Erickson, Goldthorpe e Portocarrero (1979) para uma pesquisa comparando Suécia, Inglaterra e França. 
Concluem que o país ainda estaria longe de ser uma sociedade de classe média, porque apenas um terço da população se encontra nas três classes superiores do esquema.

Os trabalhos de Pochman (2012), Souza (2012) e Scalon e Salata (2011) levantam pontos importantes que são sumamente ignorados pelo discurso ufanista sobre a nova classe média. De fato, os estudioso da estratificação social sabem que o capital cultural (geralmente mensurado pela educação dos pais e das pessoas) e a divisão do trabalho (posição na estrutura produtiva) são importantes para definir a distribuição de classe das sociedades. Essas pesquisas se colocam em oposição à de Neri (2011), na medida em que indicam que a estrutura e cultura de classe não podem ser reduzidas à renda, que a despeito de ser um indicador importante não pode ser a única forma de definir a estrutura de classes das sociedades. A estratificação social é multidimensional em qualquer sociedade, ou seja, educação, cultura de classe, ocupação, posição na estrutura produtiva e renda são dimensões distintas que estão estatisticamente correlacionadas, mas não perfeitamente alinhadas. A melhora da renda é evidente, embora o mercado de trabalho ainda inclua um enorme número de trabalhadores não qualificados que são geralmente definidos na literatura sociológica como classe trabalhadora e não como classe média (Charles; Grusky, 2004). Além disso, todos sabem que o nível educacional da população brasileira ainda é muito baixo. De fato, todas essas características apresentadas como importantes nos estudos a favor e contra a ideia de que surgiu uma nova classe média no Brasil não são contraditórias. Não há dúvidas, no entanto, de que definr classes sociais apenas pela renda é uma enorme limitação conceitual e empírica. Um dos objetivo deste artigo é mostrar que todas essas dimensões são importantes e que devem ser apreciadas em conjunto. Além disso, há uma característica que não foi levada em conta em nenhum destes trabalhos: as chances de mobilidade social. 
Em um livro sobre a estrutura de classe das sociedades modernas, Anthony Giddens (1973) resume de forma muito clara o que determinaria as classes alta, média e baixa:

the structuration of classes is facilitated to the degree to which mobility closure exists in relation to any specified form of market capacity. There are three sorts of market capacity which can be said to be normally of importance in this respect: ownership of property in the means of production; possession of educational or technical qualification; and possession of manual labour-power. [...] if these tend to be tied to closed patterns of [...] intergenerational mobility, this yields the foundation of a basic three-class system in capitalist society: an 'upper', 'middle', and 'lower'or 'working' class. (Giddens, 1973, p. 102)

De acordo com esta definição, a divisão entre classes altas, médias e baixas depende do fechamento social em termos de mobilidade intergeracional (em um regime de classes, o fechamento nunca seria total) tomando como base relações de emprego baseadas na propriedade dos meios de produção, na educação ou qualificação técnica e na força de trabalho manual. Os estudos sobre mobilidade de classe usando o esquema CASMIN se desenvolveram estreitamente ligados a esta perspectiva de Anthony Giddens. O esquema CASMIN foi desenhado para fazer distinções em torno da propriedade, da qualificação (ligada a autoridade) e do trabalho manual, e também faz a distinção entre setores urbanos e rurais. Foi explicitamente desenhado por Erickson e Goldthorpe (1993) para analisar a mobilidade social. É este esquema que utilizo para descrever a estrutura de classes no Brasil entre 1973 e 2008. Com o objetivo de contribuir para a literatura sobre a classe média no Brasil contemporâneo descrevo a estrutura de classes no Brasil utilizando o esquema CASMIN em termos de suas característica conceituais (nominais), distributivas (renda, educação e status ocupacional) e de fechamento em termos de mobilidade intergeracional. 
Embora o esquema CASMIN possa ser formulado usando os dados das PNADs (o que foi feito pela primeira vez por Ribeiro, 2007), estes dados do IBCE encontram algumas limitações para a definição das classes. Em contraste, o questionário da PDSD, que uso neste artigo, inclui todas as perguntas necessárias para definir de forma exata o esquema CASMIN, ou seja, o questionário da PDSD coletou informações sobre ocupação, tamanho das empresas, supervisão do trabalho (se supervisiona ou não o trabalho dos outros) e posição na ocupação (empregador, empregado, e conta própria). De fato, o esquema construído a partir da PDSD é mais fidedigno em relação ao esquema original do projeto CASMIN, na medida em que usa variáveis coletadas da mesma forma, usando as mesmas perguntas exigidas pela sintaxe original ${ }^{2}$. Para comparar a PDSD com as PNADs (Gráfico 1 e Tabela A1 do anexo), fiz a classificação dos dados das PNADs seguindo de perto a definição obtida pela PDSD, ou seja, parti da PDSD para a PNAD e não vice-versa. Por estes motivos, minha classificação é ligeiramente diferente daquela usada por Scalon e Salata (2011). Seguindo esses procedimentos, chego à definição de sete classes sociais: I+II, profissionais e administradores; Illa $+b$, Trabalhadores não-manuais de rotina; $\mathrm{IVa}+\mathrm{b}$, pequenos proprietários com e sem empregados; $\mathrm{V}+\mathrm{VI}$, técnicos, supervisores e trabalhadores manuais qualificados; VIla, trabaIhadores manuais não-qualificados; IVc, pequenos proprietários rurais; e VIlb, trabalhadores rurais (para a análise dos dados das mulheres agrego estas duas últimas classes). Este esquema de classes é amplamente usado na área de estratificação social e possibilita observar de forma clara e sucinta a situação de classe dos brasileiros.

Usando esse esquema, não há uma maneira simples e incontroversa de definir a classe média. Qualquer agregação entre grupos de classe é

${ }^{2}$ Para a sintaxe original ver: http://home.fsw.vu.nl/HBG.Ganzeboom/ 
relativamente arbitrária. Scalon e Salata (2011), por exemplo, agregam as classes I+II, IIla +b e IVa +b e dizem que estas são as classes médias. Esta agregação é justificável, mas não é incontroversa. Na realidade, a própria ideia de classe média, segundo a perspectiva de Giddens (1973) e de Erickson e Goldthorpe (1993), dependeria, por um lado, das distinções em termos de capacidade de mercado (propriedade, conhecimento e trabalho manual) que informam a própria elaboração do esquema e que fazem com que as classes estejam correlacionadas às variáveis de renda e educação (por exemplo), e, por outro lado, da mensuração das principais barreiras (fechamento) para mobilidade intergeracional. Em outras palavras, para determinar as fronteiras da classe média usando o esquema CASMIN, é recomendável levar em conta não apenas as distinções embutidas na definição de cada categoria, mas também a correlação com outros indicadores (renda e educação) e, sobretudo, o padrão de mobilidade intergeracional. Em suma, segundo a perspectiva sociológica, conhecer o padrão de mobilidade intergenracional é fundamental para definir as classes altas, média e baixa.

No esquema CASMIN, as pessoas nas classes de profissionais e administradores (I+II), trabalhadores não-manuais de rotina (IIla) e técnicos, supervisores e trabalhadores manuais qualificados $(\mathrm{V}+\mathrm{VI})$ possuem qualficiações educacionais ou técnica específica e, nesse sentido, estariam qualificadas para estar nas classes médias. Em princípio, as classes I+II, $\mathrm{IVa}+\mathrm{b}$ (pequenos proprietários) e IVc (pequenos proprietários rurais) se caracterizam por ter alguma propriedade, o que as qualificaria como classes altas, mas, na construção do esquema, proprietários que tenham mais de 10 empregados são classificados na classe I+II. Esse procedimento faz com que as classes IVa + b e IVc sejam compostas por pequenos proprietários que trabalham por conta própria ou empregam muito pouca gente, o que de fato as aproxima da classe média. Além, disso, no Brasil, 
os pequenos produtores rurais (IVc) são em geral mais pobres do que seus pares nos países do hemisfério norte, o que implica em dizer que estão mais próximos da classe baixa. Também por conta dos procedimentos de classificação adotados, a classe I+II (profissionais e administradores) se caracteriza não apenas por incluir indivíduos que possuem educação mais elevada e especializada, como também por incluir proprietários e empregadores com mais de 10 empregados, consequentemente a classe I+II poderia ser definida como classe alta, ou pelo menos classe média alta. Finalmente, as classes de técnicos e trabalhadorea manuais qualificados $(\mathrm{V}+\mathrm{VI})$, de trabalhadores manuais não-qualificados (VIla) e de trabaIhadores rurais (VIIb) se caracterizam por incluir indivíduos que possuem força de trabalho manual e poderiam ser definidas como classes baixas, embora a classe $\mathrm{V}+\mathrm{VI}$, que inclui técnicos e trabalhadores com alguma qualificação especializada, também possa ser definida como uma classe média. Levando em conta apenas estas distinções nominais e de construção do esquema, a classe I+II poderia ser definida tanto como classe alta quanto como classe média, e a classe $\mathrm{V}+\mathrm{VI}$ poderia estar tanto na classe média quanto na baixa. Não há dúvidas de que as classes IVa+b e IIla+b devem ser classificadas como classes médias, nem de que as classes de trabalhadores urbanos e rurais (VIla e VIlb) estariam nas classes baixas. Todas estas distinções são apenas nominais e definidas pelas formas de classificação das ocupações, ou seja, não levam em conta as características empíricas de cada classe em termos da distribuição de chances de vida. Na Tabela 1, apresento algumas informações nesse sentido, na medida em que indico a relação entre cada uma das sete classes e as distribuição de renda, educação, status ocupacional e chances de mobilidade (distância entre as classes em termos de mobilidade social de acordo com o Modelo 12 da Tabela 2). 
Sociologias, Porto Alegre, ano 16, no 37, set/dez 2014, p. 178-217

Tabela 1. Médias de Educação (anos de escolaridade), Média de Renda do Trabalho, Média de ISEI*, e escore do modelo RCII (Modelo 12, Tabela 2). Dados para homens entre 30 e 64 anos, Brasil 2008.

\begin{tabular}{l|c|c|c|c}
\hline \multicolumn{1}{c|}{ Classe } & Educ. & Renda & ISEI & RCII \\
\hline I+II - Prof. e Adm. & 13,6 & 3601,5 & 58,7 & 0,3962 \\
\hline IIla+b - Não Manual de Rotina & 10,3 & 1342,5 & 42,5 & 0,2929 \\
\hline V+VI - Técn. e Trab. Man. Qualif. & 7,7 & 1088,0 & 32,5 & 0,1215 \\
\hline IVa+b - Peq. Propriet. com e sem empreg. & 7,3 & 1199,9 & 38,3 & 0,1125 \\
\hline VIla - Trab. Manuais não-qualificados & 6,1 & 707,7 & 24,8 & 0,0734 \\
\hline Ivc - Peq. Propriet. Rurais & 5,9 & 1076,5 & 23,6 & $-0,1608$ \\
\hline VIIb - Trabalhadores Rurais & 5,8 & 687,4 & 23,7 & $-0,8358$ \\
\hline
\end{tabular}

* Inernational Socio-economic Index

Fonte: Inernational Socio-economic Index

De acordo com os dados apresentados na Tabela 1, a classe de profissionais e administradores (I+II) encontra-se em uma situação bastante privilegiada e destacada em relação a todas as outras classes, na medida em que tem: (1) a média de anos de escolaridade mais alta $(13,3),(2)$ a média de renda mais alta ( $R \$ 3601)$, (3) a média de status ocupacional mais alta (59) e (4) o escore mais elevado e destacado na escala RCII $(0,3962)$ que mede a distância entre as classes em termos de chances de mobilidade intergeracional (explicarei melhor essa escala na seção 5, em que apresento os modelos estimados). Em uma situação intermediária em termos desses quatro indicadores, encontram-se as classes de trabalhadores não-manuais de rotina (IIla $+\mathrm{b})$, técnicos e trabalhadores qualificados $(\mathrm{V}+\mathrm{VI})$ e pequenos proprietários $(\mathrm{IVa}+\mathrm{b})$. A classe $\mathrm{V}+\mathrm{VI}$ está acima da IVa $+b$ em termos de educação e chances de mobilidade (RCII), mas abaixo em termos de renda média e status ocupacional. Finalmente, temos três classes na base da distribuição em termos dos quatro indicadores mensurados: trabalhadores manuais não-qualificados (VIla), pequenos produtores rurais (IVC), e trabalhadores rurais (VIIb). A classe IVC, 
no entanto, tem renda média mais próxima do grupo intermediário de classes, embora em termos dos outros três indicadores esteja realmente mais próxima da base. Usando esses quatro indicadores, chega-se a uma situação em que a decisão sobre os grupos que comporiam a classe média não é trivial. Na verdade, há quatro agregações possíveis para determinar quais seriam as classes médias usando o esquema CASMIN. A primeira seria selecionar os grupos que estão no meio da distribuição dos quatro indicadores (educação, renda, ISEI e escore RCII), o que levaria à conclusão de que as classes médias são: IIla $+b, V+V I$, e IVa $+b$. Adotando esse critério, e somando os percentuais nas classes IIIa, V+VI e IVa+b, que são apresentados no Gráfico 1, a evolução das classes médias ao longo das décadas seria a seguinte: $26,8 \%$ em 1973, 27,8\% em 1982, 30,9\% em 1988, 30,9\% em 1996 e 36,9\% em 2008. Se incluíssemos a classe I+II nesse grupo, teríamos uma segunda agregação $(I+I I, I I l a+b, V+V I$ e IVa + b) com os seguintes percentuais nas classes médias: $38,4 \%$ em $1973,36,8 \%$ em 1982, 43,9\% em 1988, 44,5\% em 1996, e 50,8\% em 2008. Esta última perspectiva é a mais abrangente e implicaria em dizer que as classes médias alcançaram $50 \%$ da força de trabalho na década de 2000. Mas essa não é a única possibilidade, uma vez que alguns autores (Scalon; Salata, 2011) argumentam que a classe V+VI não deveria ser incluída nas classes médias, porque na realidade faz parte da classe trabalhadora ou baixa. Concordo com esta perspectiva, contanto seja ressaltado o caráter de trabalho manual, mas acho importante lembrar que, de fato, a classe $\mathrm{V}+\mathrm{VI}$, e ainda mais a $\mathrm{V}$ quando isolada, é caracterizada por ter bastante qualificação em termos de conhecimento especializado dos processos produtivos e de supervisão do trabalho dos outros (na Tabela 1, mostro que, em termos de educação e chances de mobilidade, a classe $\mathrm{V}+\mathrm{VI}$ está acima da classe $\mathrm{IVa}+\mathrm{b}$ ). Excluindo a classe $\mathrm{V}+\mathrm{VI}$, a terceira possibilidade seria agregar apenas as classes I+II, IIla + b e IVa + b nas 
classes médias, o que leva aos seguintes percentuais ao longo do tempo: 25,1\% em 1973, 23,6\% em 1982, 29,9\% em 1988, 30,9\% em 1996, e $35,2 \%$ em 2008. Reparem que, neste caso, o percentual em 2008 (usando a PDSD) nas classes médias é semelhante ao de 32,\% encontrado por Scalon e Salata (2011) usando a PNAD de 2009. Finalmente, há uma quarta possibilidade, que implica em definir apenas IIla +b e IVa +b como classes médias. Neste caso, os percentuais são: 13,5\% em 1973, 14,6\% em 1982, 16,9\% em 1988, 17,3\% em 1996, e 21,3\% em 2008.

As análises sobre mobilidade social que apresento na seção 3 deste artigo sugerem que a classe de profissionais e administradores (I+II) é a mais fechada de todas em termos de mobilidade social. Há fortes barreiras para a mobilidade integeracional para dentro e para fora desta classe e, portanto, ela é a que melhor se aproxima da ideia de fechamento social defendida por Giddens (1973) como fundamental para definir as classes altas, médias e baixas. Isso significa que, no esquema CASMIN, a classe I+II seria a classe alta. Popularmente, pessoas nesse grupo se entendem como classe média alta ou, muitas vezes, apenas como classe média - ver o excelente trabalho de Salata (2013) sobre este assunto - embora no esquema CASMIN se encontrem mais protegidas em termos de mobilidade social. São as mais fechadas e, portanto, argumento que deveriam ser separadas das outras classes que estão abaixo. Deste ponto de vista, a melhor agregação para determinar o tamanho das classes médias é a que soma IIIa +b, V+VI e IVa+b levando a 36,9\% neste grupo em 2008.

Defendo a abordagem que leva a sério a perspectiva sociológica, principalmente na sua vertente weberiana (representada pelos trabalhos de Giddens, 1973, e de Erickson e Goldthorpe, 1993), sob a qual não é possível dizer que na década de 2000 a composição da população brasileira passou a ter mais de $50 \%$ das pessoas na classe média. Nesse sentido, as análises que apresentei na Tabela 1 (a qual também inclui informações 
obtidas pelos modelos log-lineares que uso na seção 3 para analisar a mobilidade social) e no Gráfico 1 indicam que o Brasil ainda não pode ser classificado como uma sociedade de classe média. Do ponto de vista das características das ocupações e da mobilidade social - elementos fundamentais para mensurar as classes sociais na perspectiva sociológica -, o Brasil não é uma sociedade de classe média. Esta conclusão se deve, principalmente, ao fato de que há menos fluidez social entre a classe de profissionais e administradores (I+II) e todas as classes abaixo. Na ponta inferior, também há barreiras à mobilidade (menos fluidez social) entre os trabalhadores manuais não qualificados (VIla e VIIb) e pequenos agricultores (IVc), de um lado, e as classes intermediárias (IIla +b, V+VI e IVc), de outro. Barreiras que dificultam o fluxo nos dois sentidos.

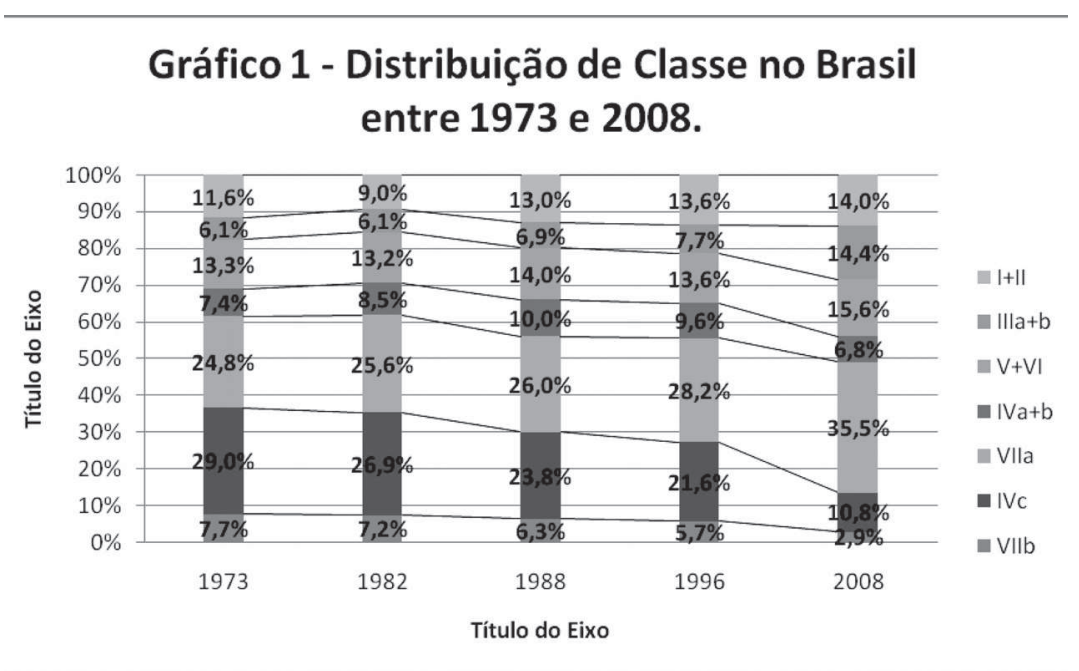

http://dx.doi.org/10.1590/15174522-016003711 


\section{Mobilidade Social}

Os estudos de mobilidade de classe fazem uma distinção entre taxas absolutas e relativas de mobilidade. As taxas absolutas refletem a disparidade entre as distribuições de classes de origem e de destino (ver Tabela A1 em anexo). Essas distribuições tendem a ser muito diferentes quando as sociedades passam por mudanças estruturais em períodos curtos de tempo. A diferença entre as distribuições de classe de origem (dos pais) e de destino (dos filhos) são muito acentuadas no Brasil, exatamente porque a industrialização e a urbanização ocorreram em um curto período de tempo no país, principalmente nas décadas de 1960 e 1970. Ecos dessa mudança ainda podem ser percebidos nas taxas de mobilidade intergeracional até 2008. Usando um esquema com seis classes sociais, Costa Ribeiro (Ribeiro, 2012) mostrou que, para os homens, em 1973, o índice de mobilidade total era de 55,3\%, em 1982 de 57,7\%, em 1988 de $60,7 \%$, em 1996 de 60,9\%, e em 2008 de 67,3\%. Esses percentuais representam a quantidade de indivíduos que está em uma classe de destino diferente da sua classe de origem.

Há dois problemas com as taxas absolutas de mobilidade. Primeiro, elas não mensuram a associação estatística entre classes de origem e de destino. Essa mensuração é importante para definir a vantagem relativa que indivíduos com diferentes classes de origem têm de ascender socialmente. Por exemplo, se a classe de profissionais e administradores quadruplicar de tamanho entre a geração dos pais e a dos filhos, e todos os filhos de profissionais (em média 2) se tornarem profissionais, teremos que pelo menos metade dos profissionais viriam necessariamente de baixo. Do ponto de vista das taxas absolutas, haveria bastante mobilidade, mas do ponto de vista das taxas relativas haveria uma enorme associação entre origem e destino de classe. Os profissionais teriam certeza de que seus filhos se tornariam profissionais. Em outras palavras, neste caso, a de- 
sigualdade de oportunidades seria a maior possível. Em segundo lugar, a análise das taxas relativas de mobilidade social permite definir mais detaIhadamente qual o padrão ou regime de mobilidade de classe que caracteriza uma determinada sociedade, ou seja, quaisl as principais barreiras e qual o grau de fechamento social. Será que o regime de mobilidade de classe no Brasil segue um padrão topológico, com classes se opondo e se separando em diferentes dimensões, ou hierárquico, com classes se separando ao longo de uma única hierarquia?

Na seção anterior deste artigo, apresentei o escore RCII, obtido pelo modelo 12 da Tabela 2, que usei para interpretar quais seriam as principais barreiras de classe na estrutura social brasileira. Nesta seção, apresento as análises que me levaram a escolher esse modelo como o melhor para explicar o padrão de fluidez e, consequentemente, o mais adequado para descrever a estrutura de classes brasileira. É importante estimar diversos modelos e compará-los hierarquicamente para chegar a um que melhor explique o padrão de mobilidade no Brasil. Essas análises são um pouco áridas para o leitor que não está acostumado à análise de dados, mas são muito importantes, porque cada modelo permite testar uma hipótese sobre o padrão de fluidez no Brasil. Como já adiantei acima, o melhor modelo foi o 12, mas é importante apresentar todos os passos que levaram a decidir sobre este modelo e, consequentemente, sobre o padrão de fluidez que ele representa.

As análises que apresento a seguir permitem definir a força da associação estatística (fluidez social) entre classes de origem e de destino e, paralelamente, definir quais são as principais barreiras à mobilidade social intergeracional que caracterizam uma determinada estrutura de classes. Em outras palavras, o uso dos modelos log-lineares permite determinar não apenas o grau da desigualdade de oportunidades (em termos de mobilidade intergeracional), como também o padrão de estruturação de classes que caracteriza uma determinada sociedade. 
De acordo com a perspectiva desenvolvida por Erickson e Golthorpe (1993), haveria um padrão topológico de associação, ou seja, um padrão determinado por três tipos de barreiras à mobilidade social: hierarquia (entre alguns grupos de classe), herança (propensão a imobilidade), e divisão entre setores (setores rurais versus urbanos, e classes com versus classes sem acesso à propriedade dos meios de produção). Além disso, Erickson e Golthorpe (1993) definem algumas afinidades, aproximando classes, e não-afinidades, separando outras classes. Estes dois últimos aspectos deveriam ser definidos de acordo com as características históricas de cada sociedade. Com base nestas quatro características, Erickson e Goldthorpe (1993) sugerem que haveria um modelo básico capaz de descrever, com algumas variações mínimas, o padrão de fluidez social em todas as sociedades industriais. Eles denominam este modelo de core social fluidity model.

O core model foi criticado logo ao nascer (Hauser; Hout, 1992) por dois motivos. Primeiro, o modelo seria definido de forma ad hoc, na medida em que a inclusão dos termos de afinidade força artificialmente o ajuste aos dados, sem que haja uma definição teórica destes termos a priori. Ou seja, primeiro incluímos os termos (em geral a partir da inspeção dos resíduos do modelo) para que se ajustem bem aos dados e, em seguida, propomos uma explicação substantiva para o uso destes termos. Segundo, os críticos afirmam que a hierarquia entre as classes não é totalmente explorada, ou seja, o core model hierarquiza apenas três grupos de classe (em uma tabela com sete categorias de classe) ao invés de explorar possíveis hierarquias entre todas as classes. Dessa forma, diversos autores sugerem que algum modelo hierarquizando as classes e incluindo termos para imobilidade seria mais adequado para descrever o regime de mobilidade em diversas sociedades modernas (Ganzeboom; Luijkx; Treiman, 1989; Hout, 1988; Szelényi, 1998; Torche, 2005).

A controvérsia opondo os dois tipos de padrão de associação (topológico ou hierárquico) como melhor descrição do regime de mobilidade 
em sociedades industriais nunca chegou a uma solução. Em geral, o padrão hierárquico parece ser o preferido pela maior parte dos pesquisadores (Ganzeboom; Luijkx; Treiman, 1989; Hout, 1988; Szelényi, 1998; Torche, 2005), embora o padrão topológico seja bastante informativo em pesquisas comparativas (ver também Ishida, 2005; Breen, 2007). Apresento a seguir o ajuste de diversos modelos a duas tabelas de mobilidade: uma com sete categorias de classe para homens, e outra com seis categorias de classe para mulheres ${ }^{2}$. Meu principal objetivo é definir qual tipo de padrão, topológico ou hierárquico, melhor descreve o regime de mobilidade no Brasil.

Os ajustes de diversos modelos log-lineares à tabela de mobilidade intergeracional cruzando sete classes de origem por sete de destino para homens são apresentados na Tabela 2. Para avaliar o modelo que melhor se ajusta aos dados, uso duas estatísticas de ajuste o $\mathrm{G}^{2}$ e o Bic. A primeira se distribui como qui-quadrado e a segunda é uma medida bayesiana (quanto mais negativa, melhor o ajuste). O primeiro modelo que ajustei é o de independência, segundo o qual não haveria associação entre classes de origem e de destino. Como de costume em análises sobre mobilidade social, esse modelo não se ajusta bem aos dados, o que significa que classes de origem e destino estão associadas. O segundo modelo (quase independência) especifica termos de imobilidade para cada uma das sete células diagonais. Este segundo modelo é o primeiro a se ajustar aos dados de acordo com a estatística Bic (-72,9); além disso, explica 77\% da associação não explicada pelo modelo de independência, ou seja, 77\% da associação entre origem e destino se deve à imobilidade social.

${ }^{2}$ Uso apenas seis categorias para as mulheres porque praticamente não há mulheres na classe de proprietários rurais. 
Tabela 2. Estatísticas de ajuste de modelos log-lineares de mobilidade social. Homens entre 25 e 64 anos, Brasil.

\begin{tabular}{|c|c|c|c|c|c|}
\hline Modelos & G2 & g. I. & $\mathrm{BIC}$ & p-value & $\begin{array}{c}\text { Disim. } \\
(\%)\end{array}$ \\
\hline 1. Independência & 676,2 & 36 & 392,6 & 0,000 & 16 \\
\hline 2. Quasi-independência & 155,8 & 29 & $-72,9$ & 0,000 & 6,7 \\
\hline 3. Quasi-independência + associacão uniforme & 88,8 & 28 & $-131,7$ & 0,000 & 5,1 \\
\hline 4. Quasi-independência + linha-por-linha (renda) & 155,4 & 28 & $-65,2$ & 0,000 & 6,7 \\
\hline $\begin{array}{l}\text { 5. Quasi-independência + linha-por-linha (escola- } \\
\text { ridade) }\end{array}$ & 73,9 & 28 & $-146,6$ & 0,000 & 3,8 \\
\hline $\begin{array}{l}\text { 6. Quasi-independência + linha-por-linha (renda }+ \\
\text { escolaridade) }\end{array}$ & 73,8 & 27 & $-138,8$ & 0,000 & 3,8 \\
\hline $\begin{array}{l}\text { 7. Quasi-independência + linha-por-linha (isei pais, } \\
\text { isei filhos) }\end{array}$ & 92,9 & 28 & $-127,5$ & 0,000 & 4 \\
\hline 8. Quasi-independência + RCII (linhas e colunas dif.) & 27 & 18 & $-114,7$ & 0,079 & 2,6 \\
\hline $\begin{array}{l}\text { 9. Quasi-independência + "equal" RC-II (linhas e } \\
\text { colunas iguaies) }\end{array}$ & 38,9 & 23 & $-142,2$ & 0,020 & 2,7 \\
\hline 10. Core model de Erikson e Goldthorpe & 59,7 & 28 & $-160,8$ & 0,000 & 5,3 \\
\hline $\begin{array}{l}\text { 11. Core model com adaptação para trabalhadores } \\
\text { rurais }\end{array}$ & 41,3 & 27 & $-171,3$ & 0,039 & 4 \\
\hline $\begin{array}{l}\text { 12. Diagonal (geral, I+II e IVC) + RCII (linhas e } \\
\text { colunas dif.) }\end{array}$ & 27,8 & 22 & -145 & 0,182 & 2,7 \\
\hline $\begin{array}{l}\text { 13. Diagonal (geral, I+II e IVC) + "Equal" RCII } \\
\text { (linhas e colunas dif.) }\end{array}$ & 40 & 27 & $-172,6$ & 0,051 & 2,9 \\
\hline & & & & & \\
\hline
\end{tabular}

Os modelos seguintes ( 3 a 9) são todos baseados na noção de que as classes de origem e de destino estão ordenadas hierarquicamente. São estes modelos que testam a ideia de que o padrão de mobilidade brasileiro é baseado na hierarquia entre as classes e na imobilidade. A diferença entre eles é a forma de hierarquização adotada. O modelo 3 testa a hipótese de que as classes estão ordenadas com distâncias iguais entre cada uma delas (uniform association) e que em cada célula diagonal há 
um padrão de imobilidade distinto. Esse modelo (3) melhora o ajuste em relação ao modelo 2 (quase independência) que o precede na hierarquia entre modelos. Os modelos 4, 5, 6 e 7 hierarquizam as classes de acordo, respectivamente, com a renda média em cada classe, a escolaridade média em cada classe, a renda média mais a escolaridade média em cada classe, e a média de status socioeconômico (ISEI) em cada classe. Todos se ajustam de alguma forma aos dados segundo a estatística Bic (todas negativas), mas nenhum de acordo com a estatística $\mathrm{G}^{2}$.

O modelo 8 é o primeiro a se ajustar aos dados de acordo com a estatística $G^{2}\left(G^{2}=27\right.$, g.l. $=18$, e p-value $\left.=0,079\right)$. Este modelo é denominado quase-independência, com padrão de associação RC-II (ordenação distinta para classes de origem e de destino) e testa a hipótese de que há uma hierarquia entre as classes de origem e outra entre as classes de destino, sendo que ambas são obtidas a partir da associação entre origem e destino. Além disso, as distâncias entre classes são distintas para origem e destino e também há parâmetros para imobilidade. O modelo 9, que impõe uma ordenação idêntica para classes de origem e de destino, não se ajusta tão bem quanto o 8 .

Os modelos 12 e 13 simplificam o 8 e 9, respectivamente, e melhoram bastante o ajuste. A diferença é que ambos especificam apenas três termos de imobilidade: um para imobilidade na classe I+II (dos profissionais e administradores), outro para imobilidade na classe IVc (pequenos agricultores), e um terceiro para imobilidade nas classes IIlab, IVac, V+VI, VIla e VIIb. A classe I+II é a de profissionais e administradores, que ficam no topo da estrutura de classes e que têm vários recursos (capital cultural, social e econômico) em abundância, o que facilita a imobilidade intergeracional. A classe IVc é a de pequenos proprietários rurais que geralmente transmitem suas terras para seus filhos, o que implica em forte imobilidade intergeracional. Faz sentido, portanto, que a imobilidade seja diferenciada nestas duas 
classes, enquanto, para as outras, a imobilidade pode ser capturada por um único termo, uma vez que não há processos sociais específicos determinando a transmissão intergeracional de classe. Além disso, o modelo 12 especifica distâncias distintas para classes de origem e de destino, enquanto o 13 especifica distâncias iguais entre as classes de origem e as de destino. O modelo 12 é o que melhor se ajusta aos dados entre todos estimados e apresentados na Tabela 2. Antes de interpretá-lo, no entanto, apresento o ajuste dos core social fluidity models (modelos topológicos).

O modelo 10 é o modelo definido por Erickson e Goldthorpe (1992), o core social fluidity model, que inclui os seguintes termos: uma barreira hierárquica entre a classe I+II (profissionais e administradores) e todas as outras abaixo (HI1), uma barreira hierárquica entre a classe V+VI (trabalhadores manuais qualificados) e todas as abaixo (HI2), uma separação entre as classes urbanas (I+II, IIlab, IVab, V+VI e VIla) e as rurais (IVc e VIIb) (SE), uma barreira (não afinidade) entre as classes possuindo propriedade (I+II, IVab e IVC) e as outras (IIlab, V+VI, VIla e VIIb) (AF1), e uma afinidade aproximando as classes no setor white-collar (I+II, IIlab, IVab). Este modelo se ajusta aos dados, se avaliado pela estatística Bic, mas não pela estatística $\mathrm{G}^{2}$. O modelo 11, inicialmente apresentado por Ribeiro (2007), inclui um termo de não-afinidade específico para o caso brasileiro, o qual aumenta a distância entre a classe de origem de trabalhadores rurais (VIIb) e as classes I+II (profissionais e administradores) e IIlab (trabalhadores não-manuais de rotina). Estes dois modelos não se ajustam melhor aos dados do que os modelos 8, 12 e 13, o que me leva a concluir que um padrão hierárquico descreve melhor o regime de mobilidade no Brasil do que um padrão topológico (core social fluidity model). Ou seja, a hierarquia entre todas as sete classes explica melhor o padrão de mobilidade intergeracional no Brasil do que todos os contrastes do core model. 
Sociologias, Porto Alegre, ano 16, no 37, set/dez 2014, p. 178-217

Tabela 3. Parâmetros estimados pelo modelo 12 (RCII dif +3 heranças) da Tabela 2 para homens; e pelo 14 (RCII dif +1 herança) da Tabela 4 para mulheres. Para homens tabelas de mobilidade $7 \times 7$ e para mulheres $6 \times 6$.

\begin{tabular}{|c|c|c|c|c|}
\hline \multicolumn{3}{|c|}{ Modelo 12: Homens } & \multicolumn{2}{|c|}{$\begin{array}{l}\text { Modelo } 14 \text { (Tabela 4): } \\
\text { Mulheres }\end{array}$} \\
\hline \multicolumn{3}{|c|}{$\begin{array}{c}\text { Diagonal (geral, I+II e IVc) }+ \text { RCII } \\
\text { (linhas e colunas dif.) }\end{array}$} & \multicolumn{2}{|c|}{$\begin{array}{c}\text { Diagonal (geral, I+II) + } \\
\text { RCII (linhas e colunas } \\
\text { iguais) }\end{array}$} \\
\hline & coef. & R.C. & & coef. \\
\hline Associação & 4,469 & 87,295 & Associação & 3,092 \\
\hline Herança geral & 0,24 & 1,271 & & \\
\hline Herança I+II & 0,423 & 1,527 & Herança I+II & 0,796 \\
\hline Herança IVc & 1,813 & 6,129 & & \\
\hline \multicolumn{3}{|l|}{ Hierarquias } & \multicolumn{2}{|l|}{ Hierarquias } \\
\hline Classes & $\begin{array}{l}\text { Origem } \\
\text { (linhas) }\end{array}$ & $\begin{array}{l}\text { Destino } \\
\text { (colunas) }\end{array}$ & Classes & $\begin{array}{l}\text { Origem } \\
\text { e Destino }\end{array}$ \\
\hline $\mathrm{I}+\mathrm{II}$ & $-0,4507$ & $-0,3962$ & $I+I I$ & $-0,429$ \\
\hline $\mathrm{IIl} a+\mathrm{b}$ & $-0,3031$ & $-0,2929$ & $\mathrm{III} a+\mathrm{b}$ & $-0,3$ \\
\hline $\mathrm{V}+\mathrm{VI}$ & $-0,0228$ & $-0,1215$ & $\mathrm{IVa}+\mathrm{b}$ & $-0,095$ \\
\hline $\mathrm{IVa}+\mathrm{b}$ & $-0,2748$ & $-0,1125$ & $\mathrm{~V}+\mathrm{VI}$ & $-0,031$ \\
\hline VIla & $-0,06$ & $-0,0734$ & VIla & 0,009 \\
\hline IVc & 0,6173 & 0,1608 & $\mathrm{IVC}+\mathrm{VIIb}$ & 0,846 \\
\hline VIIb & 0,4942 & 0,8358 & & \\
\hline
\end{tabular}

Na Tabela 3, apresento os parâmetros estimados pelo modelo 12, aquele com o melhor ajuste aos dados brasileiros. Este modelo especifica: (1) uma hierarquia com distâncias estimadas entre as classes de origem, (2) outra hierarquia com distâncias diferentes para as classes de destino, (3) a mesma ordem entre classes de origem e de destino (este resultado não é desenhado pelo modelo, mas sim fruto da estimação), (4) um termo geral para associação entre origem e destino (que, como afirmei acima, tem es-

http://dx.doi.org/10.1590/15174522-016003711 
calas distintas), e (5) três termos de imobilidade: um para classe I+II, outro para a classe IVc, e um terceiro igual para as classes IIlab, IVab, V+VI, VIla e VIlb. A hierarquia entre as classes obtida é a seguinte do topo para a base: profissionais e administradores $(I+I I)$, trabalhadores não-manuais de rotina $($ Illa $+b)$, supervisores e trabalhadores manuais qualificados $(\mathrm{V}+\mathrm{VI})$, trabalhadores por conta própria $(\mathrm{IVa}+\mathrm{b})$, trabalhadores manuais não qualificados (VIla), pequenos agricultores por conta própria (IVC), e trabalhadores rurais (VIIb). Todos os três termos de imobilidade têm valor positivo. As chances de imobilidade são 6 vezes mais altas na classe de pequenos proprietários rurais $(\mathrm{IVC})$ do que a mobilidade para outras classes, 1,5 vezes mais altas na classe de profissionais e administradores (I+II), e 1,3 vezes mais altas nas outras classes. Além disso, a associação entre classes de origem e destino é positiva $(4,46)$. Este padrão implica fortes vantagens para quem tem origem em classes sociais hierarquicamente superiores, ou seja, implica um forte padrão de reprodução de classes entre gerações em que indivíduos com origens em classes hierarquicamente superiores têm chances muito maiores de ascender e de imobilidade, e indivíduos com origens em classes sociais hierarquicamente inferiores têm chances muito menores de ascender e chances altas de imobilidade. A imobilidade é especialmente alta na classe de pequenos produtores rurais (IVC). Segundo este modelo, a hierarquia entre as classes é central para definir o padrão de fluidez social brasileiro. Portanto, no caso brasileiro, pelo menos para os homens, é um padrão vertical que melhor descreve a fluidez social e determina a desigualdade de oportunidades. Essa conclusão implica dizer que a estrutura de classes brasileira é hierarquicamente ordenada e que as divisões entre setores (por exemplo, urbano/rural, manual/não-manual, e etc.) são irrelevantes diante da hierarquia entre as classes. De certa forma, isso significa que algumas classes realmente estão no meio da hierarquia e seriam, por assim dizer, classes médias ou 
no meio. Essas classes no meio são justamente as que apresentei na seção anterior: trabalhadores não-manuais de rotina (IIla + b), trabalhadores por conta própria (IVa $+b)$, supervisores e trabalhadores manuais qualificados $(\mathrm{V}+\mathrm{VI})$. Em outras palavras, a conclusão de que a sociedade brasileira ainda não é predominantemente de classe média é reforçada pelo padrão de mobilidade que encontrei nas análises desta seção. O mais importante, no entanto, me parece ser a ideia de que a hierarquia entre as classes e a imobilidade determinam a desigualdade de oportunidades no Brasil. Mas, esta conclusão se aplicaria também às mulheres?

No caso das mulheres entre 20 e 64 anos, usando uma tabela com seis classes de origem e seis de destino, os resultados encontrados são relativamente diferentes. Neste caso, fica difícil decidir qual é o modelo que melhor se ajusta aos dados: se é a versão brasileira do core model (modelo 11 da Tabela 4: $\mathrm{G}^{2}=10,8$, g.l.=14 e pvalue $=0,702$, $\mathrm{Bic}=-95,6$ ), ou o modelo RC-II, com três termos para imobilidade e hierarquias distintas para origem e destino (modelos 13: $\mathrm{G}^{2}=14,5$, g.I. $=18$ e pvalue $=0,696, \mathrm{Bic}=$ -123,3) ou ainda o modelo RC-II com três termos para imobilidade e hierarquias iguais (modelos 12: $\mathrm{G}^{2}=10,9$, g.I. $=14$ e pvalue $=0,694$, $\mathrm{Bic}=$ -96,2). Tendo em vista que apenas o termo para imobilidade na classe I+II é estatisticamente significativo para os modelos 12 e 13 e que as hierarquias para origem e destino são semelhantes nos dois modelos ${ }^{3}$, fiz uma modificação simples, excluindo os outros termos para imobilidade do modelo 12. Assim, obtive o modelo 14, uma versão do 12, usando apenas um termo para imobilidade, que se ajusta melhor do que todos os outros apresentados na Tabela 4 (modelos 14: $\mathrm{G}^{2}=14,5$, g.l. $=19$ e pvalue $=0,754$, Bic = -131). A conclusão, portanto, é de que também para as mulheres um padrão vertical é o que melhor se ajusta ao caso brasileiro.

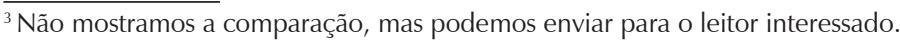


Sociologias, Porto Alegre, ano 16, no 37, set/dez 2014, p. 178-217

Tabela 4. Estatísticas de ajuste de modelos log-lineares de mobilidade social. Mulheres entre 25 e 64 anos, Brasil.

\begin{tabular}{|c|c|c|c|c|c|}
\hline Modelos & G2 & g. I. & $\mathrm{BIC}$ & $\mathrm{p}$-value & $\underset{(\%)}{\operatorname{Disim} .}$ \\
\hline 1. Independência & 395,67 & 25 & 205 & 0,000 & 13,4 \\
\hline 2. Quasi-independência & 100,4 & 19 & $-42,9$ & 0,000 & 8 \\
\hline $\begin{array}{l}\text { 3. Quasi-independência }+ \\
\text { asociaçãon uniforme }\end{array}$ & 36,3 & 18 & $-101,2$ & 0,006 & 4,3 \\
\hline $\begin{array}{l}\text { 4. Quasi-independência + linha-por-linha } \\
\text { (renda) }\end{array}$ & 44,8 & 18 & -93 & 0,000 & 4,9 \\
\hline $\begin{array}{l}\text { 5. Quasi-independência }+ \text { linha-por-linha } \\
\text { (escolaridade) }\end{array}$ & 42,3 & 18 & $-95,4$ & 0,001 & 4,6 \\
\hline $\begin{array}{l}\text { 6. Quasi-independência + linha-por-linha } \\
\text { (renda }+ \text { escolaridade) }\end{array}$ & 39,4 & 17 & $-90,7$ & 0,002 & 4,5 \\
\hline $\begin{array}{l}\text { 7. Quasi-independência + linha-por-linha } \\
\text { (isei pais, isei filhos) }\end{array}$ & 42,4 & 18 & $-95,4$ & 0,001 & 5 \\
\hline $\begin{array}{l}\text { 8. Quasi-independência + RCII } \\
\text { (linhas e colunas dif.) }\end{array}$ & 10,4 & 10 & $-66,2$ & 0,406 & 1,6 \\
\hline $\begin{array}{l}\text { 9. Quasi-independência + "equal" RC-II } \\
\text { (linhas e colunas iguaies) }\end{array}$ & 13,4 & 14 & $-93,8$ & 0,495 & 2,1 \\
\hline $\begin{array}{l}\text { 10. Core model de Erikson e } \\
\text { Goldthorpe }\end{array}$ & 37,2 & 15 & $-77,6$ & 0,001 & 4,1 \\
\hline $\begin{array}{l}\text { 11. Core model com adaptação } \\
\text { para trabalhadores rurais (Brazilian core) }\end{array}$ & 10,8 & 14 & $-95,6$ & 0,702 & 1,8 \\
\hline $\begin{array}{l}\text { 12. Diagonal }(I+I I \text { e IVC) }+ \text { RCII } \\
\text { (linhas e colunas dif.) }\end{array}$ & 10,9 & 14 & $-96,2$ & 0,694 & 1,8 \\
\hline $\begin{array}{l}\text { 13. Diagonal (I+II e IVc) + "Equal" RCII } \\
\text { (linhas e colunas dif.) }\end{array}$ & 14,5 & 18 & $-123,3$ & 0,696 & 2,1 \\
\hline $\begin{array}{l}\text { 14. Diagonal }(\mathrm{I})+\text { "Equal" RCII } \\
\text { (linhas e colunas) }\end{array}$ & 14,5 & 19 & -131 & 0,754 & 2,1 \\
\hline
\end{tabular}

Na Tabela 3, apresento os parâmetros estimados pelo modelo 14, que indicam o seguinte: (1) as hierarquias entre as classes de origem e de destino são idênticas, (2) as escalas também são idênticas, (3) o termo geral para associação entre origem e destino indica fortes barreiras verticais à mobilidade, e (4) o termo para imobilidade na classe I+II indica forte propensão para reprodução intergeracional desta classe. A hierarquia en- 
tre as classes obtida é a seguinte do topo para a base: profissionais e administradoras (I+II), trabalhadoras não-manuais de rotina (IIla + b), trabaIhadoras por conta própria (IVa+b), supervisoras e trabalhadoras manuais qualificadas $(\mathrm{V}+\mathrm{VI})$, trabalhadoras manuais não qualificadas (VIla), e pequenas agricultoras por conta própria e trabalhadoras rurais (IVc + VIIb). As chances de imobilidade são $2,2\left(\mathrm{e}^{0,796}\right)$ vezes mais altas na classe I+II do que a mobilidade para outras classes. Este padrão indica que as vantagens para quem está em classes sociais hierarquicamente superiores são muito grandes e as desvantagens nas classes hierarquicamente inferiores também são fortes. Em suma, a hierarquia entre as classes também é fundamental para definir o padrão de fluidez social das mulheres brasileiras, ou seja, é o padrão vertical, e não o topológico, que melhor descreve a fluidez social e determina a desigualdade de oportunidades no Brasil.

As análises apresentadas nessa seção levam a algumas conclusões importantes sobre o padrão de associação entre classes de origem e de destino no Brasil. Primeiro, os modelos que melhor se ajustam aos dados, tanto para homens quanto para mulheres, são aqueles que especificam uma hierarquia entre todas as classes, e não apenas entre alguns grupos de classe. O padrão vertical, e não o topológico, é o que melhor descreve o caso brasileiro. Segundo, há alta propensão para imobilidade, principalmente na classe de profissionais e administradores $(I+I I)$, que é a hierarquicamente mais alta, ou seja, a elite tem forte propensão para transmitir sua posição de classe para seus filhos. Esse padrão, com hierarquia e imobilidade no topo, indica que a estrutura social brasileira é muito rígida. Há muita mobilidade social em termos absolutos, como indiquei no primeiro parágrafo desta seção, mas forte associação entre classe de origem e de destino, como mostrei acima. Em outras palavras, a mudança rápida na estrutura de classes brasileira entre as gerações de pais e de filhos levou muitos filhos a experimentarem mobilidade social ascendente, mas aque- 
les que já se encontravam em classes hierarquicamente superiores foram capazes de garantir em larga medida essas posições superiores para seus filhos. Por exemplo, a classe de profissionais e administradores (I+II) é constituída por muitas pessoas que vieram de baixo, mas a grande maioria dos filhos de profissionais e administradores (I+II) permaneceu na mesma classe de seus pais (origem).

Este padrão de associação entre origem e destino de classe sugere que a diminuição da desigualdade de renda que vem ocorrendo no Brasil afeta pouco as pessoas que têm origem de classe na elite (classe I+II: profissionais e administradores). Pelo menos no que diz respeito às chances de mobilidade social, pessoas com origem na elite têm enormes vantagens. As mudanças que ocorreram nas últimas décadas afetam principalmente quem está nas classes abaixo, mas não os filhos de profissionais e administradores (I+II).

\section{Educação e Mobilidade Social}

A educação é o principal canal de mobilidade social nas sociedades modernas. Pessoas com mais escolaridade não só tendem a ser mais produtivas como também têm acesso a diversas ocupações que exigem qualificação específica. Por exemplo, não é possível ser um médico ou um torneiro mecânico sem ter as qualificações necessárias para exercer essas funções. Portanto, as transmissões das posições ocupacionais de pais para filhos não se dão de forma direta, mas sim através das qualificações adquiridas pelos filhos no sistema educacional. As possíveis superações das desvantagens de origem de classe também se dão, em larga medida, através da educação formal adquirida. Por exemplo, filhos de pessoas sem qualquer escolaridade e com posições de classe mais baixas têm a possibilidade de ascender, principalmente na medida em que adquirem 
qualificações educacionais. De acordo com diversas teorias em ciências sociais, a educação é o principal mecanismo de mobilidade social.

Em termos dos modelos que apresentei na seção anterior, é possível imaginar que a força da associação entre origem e destino de classe tenda a diminuir se levarmos em conta o efeito dos anos de escolaridade adquiridos pelos indivíduos. Se a educação realmente for o único mecanismo de mobilidade social, a associação entre origem e destino de classe, que descrevi acima, desaparecerá quando incluirmos os anos de educação nos modelos apresentados. Nesta seção, apresento a estimativa do efeito da educação nos modelos selecionados acima para homens (Modelo 12 da Tabela 2) e para mulheres (Modelo 14 da Tabela 4), ou seja, incluo os anos de educação alcançados como variável interveniente entre origem e destino de classe. Dentre as diversas maneiras possíveis de incluir a educação como uma variável interveniente entre origem e destino de classe, decidi estimar o efeito dos anos de educação completos pelo filho usando modelos logit multinomiais condicionais (Breen, 1994). Os modelos apresentados na seção anterior foram estimados no formato log-linear, ou seja, usando as tabelas de mobilidade cruzando classes de origem por classes de destino como dados de base. Estes mesmos modelos podem ser estimados ao nível individual a partir de uma transformação relativamente simples das tabelas de mobilidade (Breen, 1994; Hendrickx, 2000). Esta transformação permite incluir a variável anos de educação completos para cada indivíduo como variável independente nos modelos. Assim, é possível comparar os efeitos estimados pelos modelos sem e com anos de educação como variável independente.

Como mostrei na Tabela 3, o Modelo 12, para os homens, estima quatro parâmetros para descrever a associação entre origem e destino de classe. O padrão encontrado, como argumentei antes, implica forte reprodução intergeracional, favorecendo aqueles com origens nas classes sociais 
mais privilegiadas. Ao estimar este modelo incluindo a variável anos de educação completos, observei não apenas que esta variável tem um efeito positivo nas chances de mobilidade como também modifica os efeitos de herança ou imobilidade e de associação direta entre origem e destino ${ }^{4}$. De fato, cada ano de educação aumenta em 1,62 $\left(\mathrm{e}^{0,48}\right)$ vezes as chances de mobilidade ascendente. Por exemplo, um indivíduo com 15 anos de estudo completos, que completou a universidade, tem $24,3(1,62 * 15)$ vezes mais chances de mobilidade ascendente do que um indivíduo analfabeto (com nenhum ano de educação). Esse efeito deve ser somado à posição de classe de origem dos indivíduos, o que implica dizer que para classes no topo da hierarquia (por exemplo, filhos de profissionais e administradores) as chances de permanência no topo são ainda maiores. De qualquer forma, a educação aumenta enormemente as chances de mobilidade social, ou seja, pessoas com origens em classes mais baixas têm mais chances de mobilidade ascendente, na medida em que adquirem mais educação. Além disso, o efeito de imobilidade na classe de profissionais e administradores $($ I+II) deixa de ser estatisticamente significativo quando se inclui a educação dos indivíduos no modelo, ou seja, chegar ou se manter na classe de profissionais, depende da educação adquirida - mesmo a reprodução intergeracional na classe I+II depende da educação alcançada.

Apesar disso, o efeito direto das classes de origem nas de destino não desaparece quando incluímos educação no modelo, mas diminui cerca de $72 \%$ - passa de 4,47 para 1,26. Em outras palavras, as classes de origem continuam afetando os destinos de classe, o que significa que, mesmo levando em conta a educação alcançada, há desigualdade de oportunidades de mobilidade social, na medida em que indivíduos com origens em classe mais altas continuam tendo vantagens em termos de mobilidade social em relação aos indivíduos com origens em classe mais baixas.

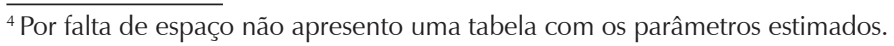


As chances de imobilidade na classe de pequenos proprietários rurais (IVc) são 6,1 vezes maiores do que as chances de mobilidade para qualquer outra classe, o que permanece praticamente inalterado quando levamos em conta a educação (6,5 vezes), ou seja, a transmissão intergeracional na classe de pequenos proprietários rurais (IVc) não depende da educação e deve ser um processo de transmissão direta de propriedade rural de pais para filhos. De acordo com o modelo que não leva em conta a educação, as chances de imobilidade nas classes de pequenos proprietários urbanos (IVab) e trabalhares qualificados e não qualificados no campo e na cidade (V+VI, VIla e VIlb) são 1,3 vezes maiores do que as chances de mobilidade para qualquer outra classe, e permanecem sendo 1,4 vezes maiores mesmo no modelo que inclui o efeito da educação, o que significa que a educação também não é relevante para a imobilidade nestas classes.

Em suma, a educação é importante tanto para alcançar ou se manter (imobilidade) na classe de profissionais e administradores (I+II), quanto para alcançar mobilidade ascendente entre as classes. Este padrão indica que a educação diminui consideravelmente as vantagens de classe, mas não elimina completamente os efeitos das classes de origem nas de destino. Continua havendo desigualdade de oportunidades mesmo quando levamos em conta a educação. Isso significa que há outros mecanismos de reprodução de classe que não passam pelo sistema educacional.

A conclusão para as mulheres é semelhante. Cada ano de educação aumenta em 1,71 ( $\left.\mathrm{e}^{0,54}\right)$ vezes as chances de mobilidade ascendente. Por exemplo, uma mulher com 15 anos de estudo completos, que completou a universidade, tem $25,7(1,71 * 15)$ vezes mais chances de mobilidade ascendente do que uma que seja analfabeta (com nenhum ano de educação), o que significa que a educação aumenta enormemente as chances de mobilidade social. Além disso, o parâmetro estimado para imobilidade na classe de profissionais e administradores (I+II) deixa de ser estatisticamente 
significativo quando levamos em conta a educação, ou seja, as chances de se manter ou chegar à classe de profissionais e administradores (I+II) dependem essencialmente da educação alcançada. Embora a educação diminua bastante o efeito das classes de origem nas de destino este efeito ainda permanece, mesmo quando levamos em conta a escolaridade alcançada pelas mulheres. Em outras palavras, a desigualdade de oportunidades de mobilidade social para as mulheres depende da classe de origem em que cresceram mesmo quando levamos em conta a educação alcançada.

Esses resultados indicam que, embora a educação seja um forte redutor da desigualdade de oportunidades, ela não é o único fator determinando estas desigualdades. Políticas de expansão educacional e de equalização do acesso aos diferentes níveis educacionais tendem a ter um forte impacto na desigualdade de oportunidades, mas há outros fatores que devem ser levados em conta. A associação direta entre classes de origem e destino, que permanece existindo para homens e mulheres mesmo quando se leva em conta a educação alcançada, pode ser consequência de diversos mecanismos. Talvez, parte da associação se deva a algum diferencial de motivação ou esforço. Não é possível descartar a hipótese de que alguns indivíduos sejam mais motivados do que outros e que isso leve a diferencial de mobilidade. Se estas características estiverem de alguma forma associadas à classe de origem dos indivíduos, então parte da associação entre origem e destino que mostrei depende deste diferencial em esforço e motivação. Outras hipóteses também relevantes são as de que haja redes de contato social favorecendo pessoas com origens nas classes mais altas e que pessoas com origens nas classes mais baixas sofram discriminação no mercado de trabalho. Ambos os mecanismos contribuiriam para a permanência da associação entre origem e destino de classe que as análises revelam, mesmo quando incluída a educação nos modelos estimados. Não há dúvida de que mais pesquisas são necessárias para 
investigar todos esses possíveis mecanismos, nem de que a educação não é a única forma de diminuir a desigualdade de oportunidades.

\section{Conclusões}

Neste artigo, procurei integrar o estudo da mobilidade e da estrutura de classes. Segundo a perspectiva neo-weberiana, representada pelos trabalhos de Giddens (1973) e Erickson e Goldthorpe (1993), é fundamental levar em conta as barreiras à mobilidade social para entender as principais clivagens de classe nas sociedades modernas. Essas barreiras constituem os principais pontos de fechamento social na estrutura de classes. Segundo esta perspectiva, atributos como propriedade dos meios de produção, qualificações educacionais ou técnicas, posição de autoridade na estrutura produtiva e força de trabalho manual são os principais recursos definindo diferentes posições de classe.

Assim, o esquema que usei parte deste tipo de distinções para determinar as posições de classe na estrutura social das sociedades contemporâneas. Para elaborar categorias de classe que possam ser usadas em pesquisas quantitativas, os atributos acima são pensados em termos das relações de emprego e mercado que definem as diferentes posições. Basicamente, há três formas de relação de emprego: empregadores (que podem ser grandes ou pequenos), trabalhadores autônomos, e empregados. Essas distinções são combinadas com ocupações diferenciadas em termos de qualificação educacional ou técnica e de supervisão do trabaIho. Além disso, o esquema inclui a divisão entre trabalho rural e urbano. A partir destas distinções conceituais e empíricas, sociólogos na área de estratificação social usam um esquema de classes que, em sua forma mais simples, classifica as ocupações nas seguintes categorias: I+II, profissionais e administradores (que também inclui grandes proprietários e empre- 
gadores); IIla $+\mathrm{b}$, trabalhadores não manuais de rotina; IVa $+\mathrm{b}$, pequenos proprietários e empregadores; $\mathrm{V}+\mathrm{VI}$, técnicos, supervisores do trabalho e trabalhadores manuais qualificados; VIla, trabalhadores manuais não qualificados; IVc, pequenos produtores rurais; e VIIb, trabalhadores rurais. Ao longo do artigo, argumentei que as distinções conceituais acima devem ser combinadas às características distributivas e de mobilidade social relacionadas às categorias de classe. Em termos das características distributivas, mostrei, na Tabela 1, que as sete categorias de classe estão correlacionadas à renda, à educação, e ao status ocupacional. De fato, ao levar em conta as correlações destas três variáveis com as sete categorias de classe, é possível perceber que os profissionais e administradores (I+II) estão em uma posição bem mais alta do que todas as outras classes, ou seja, têm renda média, status ocupacional médio e escolaridade média muito mais altas do que as encontradas para as outras classes. Na base dessas hierarquias, estão os trabalhadores manuais não qualificados (VIla) e as duas classes de trabalhadores rurais (IVc e VIIb). As classes de trabalhadores não-manuais de rotina (IIla $+\mathrm{b}$ ), pequenos proprietários urbanos (IVa+b) e técnicos e trabalhadores manuais qualificados $(\mathrm{V}+\mathrm{VI})$ estão em posição intermediária nas hierarquias de renda, educação e status ocupacional. Além disso, a distância entre as classes na base e no meio são menores do que a distância entre as classes no meio e a que se encontra no topo (I+II). Esses resultados, que são válidos tanto para homens quanto para mulheres, sugerem que a maior parte das desigualdades seria explicada pela diferença entre a classe de profissionais e administradores $(\mathrm{I}+\mathrm{II})$ e todas as outras abaixo.

No entanto, para definir as principais clivagens de classe, é necessário levar em conta não apenas aspectos conceituais e distributivos, mas sobretudo as formas de reprodução intergeracional das classes sociais. Em outras palavras, é fundamental estudar a estrutura de classes em conjunto com os padrões de mobilidade social. Para entender melhor o padrão de 
mobilidade, lancei mão de modelos log-lineares. Estas análises me levaram a concluir que as principais barreiras estão relacionadas à hierarquia entre as classes sociais e a tendências de imobilidade diferenciada nestas classes. Os modelos que melhor se ajustaram aos dados (para homens e mulheres) indicam que a classe I+II é a mais fechada de todas, ou seja, é a classe que está mais distante das outras abaixo, no que diz respeito à hierarquia, e também apresenta tendência diferenciada de imobilidade social. Isso significa que pessoas cujos pais tinham origem na classe de profissionais e administradores (I+II) têm chances muito mais altas de permanecer neste grupo do que pessoas cujos pais estavam nas classes abaixo têm de entrar na classe I+II. Em suma, as análises sobre mobilidade social indicam que a classe no topo da hierarquia (I+II) é a mais fechada de todas 5 .

Para complementar estas observações, desenvolvi análises sobre o efeito da educação alcançada nas chances de mobilidade social. Os resultados indicam que, para se manter ou chegar à classe de profissionais e administradores (I+II), é fundamental alcançar níveis educacionais mais altos, mas que, mesmo assim, indivíduos com origens nas classes mais altas continuam tendo vantagens em relação aos indivíduos com origens em classes mais baixas. A forma mais eficiente de transpor as barreiras de classe é adquirir mais escolaridade, embora filhos de profissionais e administradores (I+II) permaneçam tendo vantagens, ou seja, as barreiras à mobilidade intergeracional continuam presentes mesmo quando se leva em conta a escolaridade dos indivíduos.

Todas essas análises levam a duas conclusões muito importantes sobre a estrutura de classes brasileira. Primeiro, a estrutura de classes é composta por uma divisão clara entre o topo (classe I+II) e todas as outras classes

${ }^{5}$ Embora esta conclusão seja verdadeira é importante levar em conta que fiz distinções apenas entre sete categorias de classe. Seria muito importante fazer mais distinções, ou seja, fazer análises usando mais categorias de classe ou usando variáveis como riqueza e outros indicadores que permitam distinguir ainda mais a estrutura social brasileira. 
Sociologias, Porto Alegre, ano 16, no 37, set/dez 2014, p. 178-217

abaixo. Essa divisão se expressa tanto em termos das distribuições de renda, educação e status ocupacional quanto em termos das chances de mobilidade intergeracional. A diferença entre as classes no meio das distribuições (classes médias) e na base (classes baixas) é menor do que entre o meio (classes médias) e o topo (classes altas). De fato, as pessoas na classe de profissionais e administradores (I+II) - que têm o costume de se autodefinirem como classes médias ou classes médias altas (Salata, 2013) - estão na realidade no topo da hierarquia. Em termos das chances de mobilidade e da distribuição de ativos educacionais e financeiros, não faz muito sentido juntar profissionais e administradores (I+II) com as classes no meio da distribuição para definir as classes médias. Ou melhor, há muita diferenciação dentro das classes médias quando juntamos a classe I+II com as imediatamente abaixo. Do ponto de vista sociológico, não faz muito sentido dizer que o Brasil se tornou uma sociedade de classe média na última década.

As análises que desenvolvi também revelam que há muita desigualdade de oportunidades no Brasil. Quanto mais altas as classes de origem, maiores as chances de permanecer ou alcançar classes de destino mais altas. A educação é uma das maneiras de transpor estas barreiras, mas não elimina o efeito da classe de origem. Os modelos que usei para analisar a associação entre origem e destino de classe indicam que há fortes barreiras à mobilidade intergeracional. Essas barreiras são relativamente permeáveis, na medida em que as pessoas avançam no sistema educacional, mas não são completamente eliminadas pela educação. Mesmo quando incluída a escolaridade dos indivíduos nos modelos, o efeito das classes de origem permaneceram significativos e relativamente fortes. Em suma, para tornar a sociedade brasileira mais igualitária, é necessário desenvolver mais o sistema educacional, mas também diminuir a desigualdade de condições entre as classes sociais. Tenho esperanças de que minhas análises neste artigo tenham contribuído para mostrar que o estudo da es- 
trutura de classes no Brasil contemporâneo também deve levar em conta os padrões de mobilidade intergeracional.

\section{Anexo}

Tabela A1. Distribuição de Classe de Origem e de Desino no Brasil em 1973, 1982, 1988, 1996, e 2008. Homens e Mulheres entre 20 e 64 anos de idade.

\begin{tabular}{|c|c|c|c|c|c|c|c|c|c|c|c|}
\hline & \multicolumn{5}{|c|}{ Homens } & & \multicolumn{5}{|c|}{ Mulheres } \\
\hline & \multicolumn{5}{|c|}{ Destino de Classe (Filhos) } & & \multicolumn{5}{|c|}{ Destino de Classe (Filhos) } \\
\hline & 1973 & 1982 & 1988 & 1996 & 2008 & & 1973 & 1982 & 1988 & 1996 & 2008 \\
\hline$I+I I$ & $11,6 \%$ & $9,0 \%$ & $13,0 \%$ & $13,6 \%$ & $14,0 \%$ & $I+I I$ & $11,1 \%$ & $13,2 \%$ & $16,5 \%$ & $15,7 \%$ & $14,8 \%$ \\
\hline $\mathrm{III} a+\mathrm{b}$ & $6,1 \%$ & $6,1 \%$ & $6,9 \%$ & $7,7 \%$ & $14,4 \%$ & IIla $+b$ & $9,9 \%$ & $11,2 \%$ & $13,0 \%$ & $13,7 \%$ & $28,8 \%$ \\
\hline $\mathrm{IVa}+\mathrm{b}$ & $7,4 \%$ & $8,5 \%$ & $10,0 \%$ & $9,6 \%$ & $6,8 \%$ & $\mathrm{IVa}+\mathrm{b}$ & $2,8 \%$ & $5,5 \%$ & $6,5 \%$ & $6,7 \%$ & $4,4 \%$ \\
\hline$V+V I$ & $13,3 \%$ & $13,2 \%$ & $14,0 \%$ & $13,6 \%$ & $15,6 \%$ & $\mathrm{~V}+\mathrm{VI}$ & $12,8 \%$ & $14,4 \%$ & $14,1 \%$ & $12,7 \%$ & $9,1 \%$ \\
\hline VIla & $24,8 \%$ & $25,6 \%$ & $26,0 \%$ & $28,2 \%$ & $35,5 \%$ & VIla & $28,0 \%$ & $32,0 \%$ & $31,2 \%$ & $27,6 \%$ & $35,4 \%$ \\
\hline IVc & $29,0 \%$ & $26,9 \%$ & $23,8 \%$ & $21,6 \%$ & $10,8 \%$ & $\begin{aligned} & I V c \\
+ & V I I b\end{aligned}$ & $35,4 \%$ & $23,7 \%$ & $18,6 \%$ & $23,5 \%$ & $7,6 \%$ \\
\hline \multirow[t]{4}{*}{ VIIb } & $7,7 \%$ & $7,2 \%$ & $6,3 \%$ & $5,7 \%$ & $2,9 \%$ & & & & & & \\
\hline & \multicolumn{5}{|c|}{ Homens } & & \multicolumn{5}{|c|}{ Mulheres } \\
\hline & \multicolumn{5}{|c|}{ Origem de Classe (Pais) } & & \multicolumn{5}{|c|}{ Origem de Classe (Pais) } \\
\hline & 1973 & 1982 & 1988 & 1996 & 2008 & & 1973 & 1982 & 1988 & 1996 & 2008 \\
\hline$I+I I$ & $4,3 \%$ & $3,6 \%$ & $4,7 \%$ & $5,4 \%$ & $8,1 \%$ & $I+I I$ & $4,3 \%$ & $4,6 \%$ & $5,3 \%$ & $6,2 \%$ & $8,5 \%$ \\
\hline $\mathrm{IIla}+\mathrm{b}$ & $2,0 \%$ & $2,1 \%$ & $2,4 \%$ & $3,5 \%$ & $5,9 \%$ & IIla $+b$ & $2,1 \%$ & $2,5 \%$ & $2,8 \%$ & $3,6 \%$ & $7,1 \%$ \\
\hline $\mathrm{IVa}+\mathrm{b}$ & $6,5 \%$ & $6,8 \%$ & $6,7 \%$ & $6,2 \%$ & $6,2 \%$ & $\mathrm{IVa}+\mathrm{b}$ & $6,7 \%$ & $7,1 \%$ & $7,6 \%$ & $6,9 \%$ & $5,8 \%$ \\
\hline $\mathrm{V}+\mathrm{VI}$ & $6,6 \%$ & $6,4 \%$ & $7,7 \%$ & $8,7 \%$ & $14,9 \%$ & $\mathrm{~V}+\mathrm{VI}$ & $5,7 \%$ & $6,7 \%$ & $8,2 \%$ & $8,5 \%$ & $15,4 \%$ \\
\hline VIlla & $8,4 \%$ & $9,2 \%$ & $11,5 \%$ & $14,4 \%$ & $23,8 \%$ & VIla & $8,4 \%$ & $10,3 \%$ & $12,8 \%$ & $13,1 \%$ & $24,6 \%$ \\
\hline IVc & $7,9 \%$ & $7,9 \%$ & $7,4 \%$ & $6,8 \%$ & $4,5 \%$ & $\begin{aligned} & I V_{C} \\
+ & \text { VIIb }\end{aligned}$ & $72,9 \%$ & $68,8 \%$ & $63,1 \%$ & $61,7 \%$ & $38,6 \%$ \\
\hline VIllb & $64,3 \%$ & $64,0 \%$ & $59,6 \%$ & $54,9 \%$ & $36,6 \%$ & & & & & & \\
\hline
\end{tabular}

Dados das PNADs de 1973, 1982, 1988 e 1996; e da PDSD 2008 
Sociologias, Porto Alegre, ano 16, no 37, set/dez 2014, p. 178-217

Carlos Antonio Costa Ribeiro. Doutor em Sociologia - Columbia University (2002). Professor e pesquisador da Universidade do Estado do Rio de Janeiro e membro do Núcleo Interdisciplinar de Estudos sobre Desigualdade - NIED (Grupo de Pesquisa do CNPq). Coordenador do Programa de Pós-graduação em Sociologia do Istituto de Estudos Sociais e Políticos da UERJ. $\longrightarrow$ carloscr@iesp.uerj.br

\section{Referências}

1. BLAU, P. M.; DUNCAN, O. D. The American occupational structure. New York: Wiley, 1967.

2. BREEN, R. Individual Level Models for Mobility Tables and Other Cross -Classifications. Sociological Methods and Research 23, p. 147-73, 1994.

3. BREEN, R. Social Mobility in Europe. Oxford: Oxford University Press, 2004.

4. CHARLES, M.; GRUSKY, D. B. Occupational ghettos: the worldwide segregation of women and men. Stanford, California: Stanford University Press, 2004.

5. ERICKSON, R. The Constant Flux: A Study of Class Mobility in Industrial Societies. Oxford: Clarendon Press, 1993.

6. ERICKSON, R.; GOLDTHORPE, J. H. The CASMIN Project and the American Dream. European Sociological Review, n. 8, p. 283-306, 1992a.

7. ERICKSON, R.; GOLDTHORPE, J. H. Comments on Sorensen 'Rejoinder'. European Sociological Review, n. 8, p. 311-312, 1992 b.

8. FEATHERMAN, D. L.; JONES, F. L.; HAUSER, R. Assumptions of Social Mobility Research in the U.S.: The Case of Ocuppational Status. Social Sciences Research, n. 4, p. 329-360, 1975.

9. GANZEBOOM, H. B.G.; LUIJKX, R.; TREIMAN, D. Integrational Class Mobility in Comparative Perspective. Research in Social Stratification and Mobility, n. 8, p. 3-84, 1989.

10. GIDDENS, A. The Class Structure of the Advanced Societies. Harper Collins Publishers, Inc, 1973.

11. GOLDTHORPE, J. H. On Economic Development and Social Mobility. British Journal of Sociology, n. 36, p. 549-573, 1985.

12. GOLDTHORPE, J. H.; LLEWELLYN, C.; PAYNE, C. Social mobility and class structure in modern Britain. Oxford: Clarendon Press, 1987.

13. HAUSER, R. M.; LOGAN, A. How to Mesasure Intergenerational occupational Persistence. American Journal of Sociology, n. 97, p.1689-1711, 1992. 
Sociologias, Porto Alegre, ano 16, no 37, set/dez 2014, p. 178-217

14. HENDRICKX, J. Special restriction in Multinomial Logistic Regression. Stata Technical Bulletin, n. 56, p. 18-26, 2000.

15. HOUT, M. Status, Autonomy and Training in Occupational Mobility. American Journal of Sociology, v. 89, n. 3, p.1379-1409, 1984.

16. HOUT, M. More Universalism, Less Structural Mobility: The American occupational Structure in the 1980's. American Journal of Sociology, n. 93, p.13581400, 1988.

17. HOUT, M. Following in Father's Footsteps. Cambridge: Harvard University Press, 1989.

18. HOUT, M.; HAUSER, R. Symmetry and Hierarchy in Social Mobility: A Methodological Analysis of the CASMIN Model of Class Mobility. European Sociological Review, n. 8, p. 239-266, 1992.

19. ISHIDA, H. Social Stratification and Social Mobility in Late-Industrializing Countries. Tokyo: University of Tokyo, 2005.

20. NERI, M. A Nova Class Média: o lado brilhante da base da pirâmide. Rio de Janeiro: Editora Saraiva, 2011.

21. PARSONS, T. A Reviseted Analytical Approach to the Theory of Social Stratification. In: Bendix, R; Lipset, S. M. Class, Status and Power. New York: Free Press, 1954.

22. POCHMANN, M. Nova Classe Média? O trabalho na base da pirâmide social brasileira. São Paulo: Boitempo Editorial, 2012.

23. RIBEIRO, C. A. C. Estrutura de Classe e Mobilidade Social no Brasil. Bauru: EDUSC, 2007.

24. RIBEIRO, C. A. C. Quarenta Anos de Mobilidade Social no Brasil. Dados, n. 55, p.641-679, 2012.

25. SCALON, M. C. Mobilidade Social no Brasil: Padrões e Tendências. Rio de Janeiro: Revan-Ipuerj-UCM, 1999.

26. SCALON, C.; SALATA, A. Uma nova classe média no Brasil da última década? O debate a partir da perspectiva sciológica. Revista Sociedade e Estado, v. 27, p. 387-407, 2011.

27. SALATA, A. Quem é 'Classe Média' no Brasil? Um estudo sobre identidades de classe. In: XVI Congresso Brasileiro de Sociologia, 2013, Salvador. XVI Congresso Brasileiro de Sociologia, 2013. v. 1. p. 152-152.

28. SOUZA, J. A Ralé Brasileira: quem é e como vive. Belo Horizonte: Editora UFMG, 2012. 
Sociologias, Porto Alegre, ano 16, no 37, set/dez 2014, p. 178-217

29. SZELÉNYI, S. Equality by Design: The Great Experiment in Destratification in Socialist Hungary. Stanford: Stanford University Press, 1998.

30. TORCHE, F. Unequal but Fluid: Social Mobility in Chile in Comparative Perspective. Americans Sociological Review, n. 70, p. 451-471, 2005.

31. TREIMAN, D. Industrialization and Social Stratification. In: LAUMANNN, E. Social Stratification: research and Theory for the 1970's. Indianapoles: BobbsMerril, 1970.

Recebido em: 27/12/2013

Aceite final: 16/05/2014

http://dx.doi.org/10.1590/15174522-016003711 